\title{
The use of modern digital technologies in humanitarian universities as a requirement for the implementation of an activity-based approach in teaching
}

\author{
E. Sh. Bekirova ${ }^{1 *}$, S.N. Bekirov ${ }^{2}$, and M.N. Harabadjah ${ }^{3}$ \\ ${ }^{1}$ V.I. Vernadsky Crimean Federal University, Simferopol, Russia \\ ${ }^{2}$ V.I. Vernadsky Crimean Federal University, Simferopol, Russia \\ ${ }^{3}$ V.I. Vernadsky Crimean Federal University, Simferopol, Russia
}

\begin{abstract}
In this article the attention is paid to the need of revising the training system for specialists in humanitarian spheres. The purpose of the article is to analyze the implementation of e-learning and the formation of an e-culture of specialists in professional organizations, to study the ways of developing students' independence by means of information and communication technologies, the usage of computer tools and systems for protecting digital resources, as well as the studying of e-learning introduction and the formation of an electronic culture of specialists in professional organizations.
\end{abstract}

\section{A problem statement}

The digital transformation of education is an obvious global trend. In the context of globalization of higher education, the market for digital educational services is growing rapidly, the range of applications of digital technologies in various formats is expanding hybrid learning, Massive Open Online Courses (MOOCs), various hybrid models. New didactic learning formats that adapt to the changing behavior of learners have become more widespread than traditional learning formats. According to a survey of 250 university representatives from 37 countries conducted by the European Association of Universities (EUA) [1], 91\% of universities successfully use hybrid students' learning systems, and $82 \%$ are simultaneously implementing distance learning technologies for distance modeling of their students.

Modern digital technologies allow universities from all around the world to interact online and to implement courses from other universities, thereby increasing the availability and quality of education. In Russia online education is a part of the state policy in the field of education, which is one of its priority areas [2]. Universities that want to become strong educational clusters should prepare progressive interactive courses with elements of distance learning [3]. The modern paradigm of education requires the implementation of

${ }^{*}$ Corresponding author: prof-ped.gpa@mail.ru 
serious reforms in higher education system by creating smart universities to form an intellectual educational environment, therefore, giving each student the opportunity to build up a profile of personality abilities, he will enter the labor market in the context of digital economy and will be in demand there [4].

Even the external conditions concerned with the pandemic viral infection forced universities and the entire education system to change quickly to online education in various formats. Some changes were also included to the Federal Law dated on December 29, 2012 No. 273-FL "On Education in the Russian Federation" that define the authority to establish the use of electronic and distance learning technical procedures in the implementation of educational programs. In this context, the issue of empirical assessment of all aspects of learning in the digital educational space is of particular relevance.

The form of studying.

The authors note that new didactic learning formats that adapt to the changing behavior of learners are more widespread than traditional ones. The purpose of the teaching technology is to improve the quality and efficiency of the educational process of students studying at universities for the Humanities and their branches on the basis of the usage of modern electronic means and information resources of the Internet.

There are many manuals on computer science and textbooks for the humanities that are devoted to popular information technologies and differ from textbooks on computer science for technical universities in the volume and accuracy of the explanation of the material. Nowadays the main task of humanists is to provide a connection between the modern scientific and technical system and culture, to create conditions for the humanistic integration of scientific and technical achievements of the Sciences into the cultural space. When performing this task humanitarians use only natural languages, in contrast to representatives of the Sciences who use artificial sign systems for carrying out their professional activities: mathematical languages, programming languages, information languages. But all these languages, including natural ones, are symbols, the general laws of which are regulated by Semiotics.

\subsection{The objective of the work}

In the context of the subject of our research, we will consider the content of the activity method in learning. We consider the method of activity as a practical guideline of modern higher education, which determines the organization of the university educational process, the variability of its content, the strengthening of its connection with practice, as search and self-determination of personality in vigorous activity aimed at identifying the basic forces that satisfy the spiritual and physical needs of students by integrating them into various types of activities (educational, social, practical).

The effectiveness of using the activity method in the professional training of students is confirmed by the fact that this method is the leading method in modern education. Its essence becomes apparent in the conditions of using of all pedagogical means, technical and organizationally intensive types of activities, constantly becoming more complex, containing new elements of personality development, ensuring the solution of certain important problems. The main characteristics of the activity provide the student's transition to the position of the subject, initiate his positive attitude to the surrounding reality, through which the student learns the world, science and culture, cognitive and social transformations in such a way that forms and improves personal development.

As a form of existence and a way of survival, activity creates material conditions for human life, satisfies a man's natural needs, becomes a factor in the development of the spiritual world, forms and creates conditions for the realization of his cultural needs and is a ground for realization of personal potential, achieving life goals and success [2]. 
The scientific concepts that make up the theory of activity make it possible to point out that the intensity and dynamics of professional training depend largely on the degree of a student's activity. Therefore, the epistemological and practical aspects of the category "activity" are of particular importance. The epistemological significance of this category lies in the fact that it allows you to analyze the dynamics of professional training as a process of self-education of a student, during which he independently resolves and overcomes contradictions of a personal and social nature. The principle of activity allows one to overcome the point of view of the individual as an object of passive manipulation, the qualities of which are clearly defined by external requirements and are the result of external influences (environment, ideology, educational institutions, etc.). Activity is a means of entering society and culture, as well as a way of self-realization of the subject [4].

Taking into account the specifics of the activity approach we consider the professional training of students from a versatile perspective, distinguishing various types of activities that "determine the level of personality development of students as subjects of education: specially organized educational and research activities; educational and social practice (all types of practice); students' activities on mastering the integrated content of higher professional education, realizing their personal, academic and social potential; management activities of teachers (departments, teachers, universities); other activities related to the providing and improvement of the process of professional training of students" [4].

It is in this connection that we see the practical pedagogical aspect of the problem, the essence of which is to search for the content, mechanisms and methods of mastering the natural environment of society at the micro-, meso- and macro-levels in various cultural spheres, corresponding to the subject's ability to perform the assigned task, to the status, capabilities, attitudes, testifying to the diversity and effectiveness of various types of activities, providing a high degree of self-organization of professional and social activities. Due to immersion in a rich palette of various forms, methods and types of activities, the social and professional thinking of students is formed, the initiative is developed, as well as the ability to manage the activity leading to success, the ability to predict the accomplishment of functions in society independently.

In accordance with the above mentioned, from the point of view of the method of activity, it is necessary to clarify the following statements, which are important for the professional training of students [5]:

1) In the context of the implementation of the method of activity in the learning process, the student appears as a subject of diverse activities, capable of active perception of the world, of oneself and one's place in the world, of optimizing relations in the "socialpersonal" system;

2) The effective professional training of a student is based on the implementation of the main types of activities (cognitive, transformative, value-oriented, communicative, aesthetic), spiritual and informational interaction, social relations, relations between members of the teaching staff, which determine the general process of transformation of the student's micro- and macroenvironment, which closely interact, influence and determine each other, including himself in accordance with the needs, goals and forms of life;

3) Changes in the activities and students' lifestyle ensure the conscious development of various social statuses and roles in the system of social structure, the main of which are: professional (professional or labor socialization), marriage and family status (family socialization), civil (political socialization), male and female (gender role socialization), religious status (religious socialization), etc.;

4) The self-transformation of social and internal conditions for student self-development coordinates the process of social integration, personalization in the educational process of the university (that is, from the activities of a general department to personalized activities on the topic). 
In our opinion, in the context of the method of activity, the idea of advanced education by V.V. Davydov is relevant, implying the degree of creative mastering of basic knowledge, which allows a person to "go beyond and form the level of development of production, engineering and technology" in relation to lifelong education [7].

Therefore, the method of activity in humanitarian education contains the initial point of view that the organization of the educational process of the university should include various types of activities that are of interest to the student, that determines the implementation of the method of activity in vocational training in the context of the identified opportunities (variability of the organization of the content of the student's activity in the university).

\section{Results of the research}

The comparative empirical study of students' attitude to learning in the format of e-learning courses "Mathematical Methods in Psychology" (ELC MMiP) and "Statistical and Mathematical Methods in Psychological and Pedagogical Research" (ELC SaMMiPaPR), developed by M.G. Sorockova and posted on the LMSMoodle platform at http://elearning.mgppu.ru/, was held at the Federal state budgetary educational institution of higher education "Moscow State Psychological and Pedagogical University" (FSBEI HE MSPPU) within the framework of the research project "Digital technologies in higher education: development of technology for individualization of teaching by means of electronic training courses". Both of these courses include 3 identical compulsory modules for the studying of basic methods of mathematical statistics; the second of them also contains an additional 4th module devoted to the methods of multidimensional statistics. In our study the opinions of students of the Federal State Autonomous Educational Institution of Higher Education "V.I. Vernadsky Crimean Federal University" were compared after completing the first 3 modules. The model of mixed learning "An inverted classroom" was used, which assumes the transition from the centering of the educational process on the teacher to the situation when the focus of attention is on the student's independent activity, the process of learning itself.

According to this model, two groups of students listened to video recordings of lectures at home and updated new information in a positive and interactive form at the seminar students solved cases in the field of psychological and pedagogical research on a computer in the SPSS statistical package, answered teacher's questions and discussed difficult material. The internal reports of ELC-online - an entrance test, 3 study tests, an online final test and individual case tasks for 6 case assignments - students also perform independently outside the classroom.

The topics of research: Attitude of two categories of students to learning in the digital environment of a humanitarian university - on the one hand, the first year of the master's degree and the third year of the second higher education degree, on the other hand, the bachelor's degree and the first higher education degree.

The tasks: 1) To determine the advantages, disadvantages and possible difficulties in studying of the ELC, comparing it from the point of view of students of the first higher education degree of full-time department with students of the master's degree and the second higher education degree;

2) To evaluate the interaction and participation in the educational process from the point of view of students of the first higher education degree of full-time department with students of the master's degree and the second higher education degree;

3) To compare the attitudes of these two types of students towards learning in the ELC format to find similarities and differences. 
The hypothesis. Undergraduates and university-based students will face greater difficulties in studying ELC than students of the first higher education degree and their attitude to the format of the e-course will be more skeptical.

The sample included 161 students (including 17.4\% of men and $82.6 \%$ of women) of the first year of the Master's program "Psychology and Pedagogy" and the third year of the second higher education degree of the direction "Psychology"), as well as 183 students (including $18.6 \%$ of boys and $81.4 \%$ of girls) of the third year of the bachelor's degree of the direction "Psychology" and specialization "Clinical Psychology".

The total sample range was 344 students. The age difference between the two groups was significant. Group EG1 mainly consists of adults: $17.4 \%$ - students aged 20-24 years, $13.0 \%$ - 25-29 years old, $24.8 \%$ - 30-34 years old, $44.7 \%-35$ years old and older, while $16.9 \%$ are young people under the age of $20,81.4 \%$ are $20-24$ years old and only $1.6 \%$ are 25 years old, and the nature of employment varies greatly between these two groups. In EG1, in comparison with EG2, work is related to the profession they are trained in, in $51.6 \%$ versus $5.5 \%$, it is irrelevant - in $31.7 \%$ versus $41.5 \%, 16.8 \%$ versus $53.0 \%$ currently do not work at all. The results: Students from EG1 spend more time working independently at the EUS: from 1 to 3 hours per week - almost the same among the respondents, i.e. $49.7 \%$ versus $55.7 \%$, more than 3 hours a week - already $34.2 \%$ versus only $9.3 \%$. Less than 1 hour of independent work per week is conducted by every fifth student from EG1 and less than $10 \%$ of students from EG2. When assessing possible learning difficulties in ELC, $69 \%$ of students from EG1 and $66.7 \%$ of students from EG2 denied that it was difficult for them to work in ELC without the help of a teacher, and about one fifth of the respondents in both groups agreed with this, and only $8.7 \%$ of students from EG1 and $12.6 \%$ of students from EG2 fully agreed $(\mathrm{p}<0.05)$. Figure 1 depicts two distributions showing the number of students in two groups for each type of response.

Difficulties in time management were recognized by $40.4 \%$ in EG1 and $41.6 \%$ in EG2, while in the second group the percentage of absolutely positive answers was higher. $82.6 \%$ of students from EG1 deny the difficulty of getting used to the new format of ELC, while in EG2 the quota of such students is somewhat less $-71.6 \%$. Only about $10 \%$ of respondents in both categories mentioned technical difficulties in online learning. We should note that in the last 3 cases, the difference was found only at the trend level $(\mathrm{p}<0.1)$. As a result, the overwhelming majority of students in both groups did not experience obvious difficulties.

Assessing the advantages of testing in the EQ study, 36.0\% and $57.8 \%$ of students from EG1 gave answers "quite yes" and "yes", while among students from EG2 there were slightly fewer answers of this kind $-33.3 \%$ and $48.6 \%$ respectively. Those who tested did not win $-18.1 \%$ in EG2 and only $6.2 \%$ in EG1. To assess the subjective impression of the difficulty of reporting emotional intelligence, we asked students to rate the difficulty of each of the 5 reporting parameters on a scale of 4 points - an introductory test, three academic tests, a final test, and an individual case. In comparison with students of the first higher education degree, the students of the master's degree and the second higher education degree showed significantly higher values of the subjective complexity of reporting -15.8 versus 14.57 (Mann-Whitney U-test, $\mathrm{p}<0.02$ ). But there was no sex difference (Mann-Whitney, $\mathrm{p}=0.329$ ) (Figure 1). 


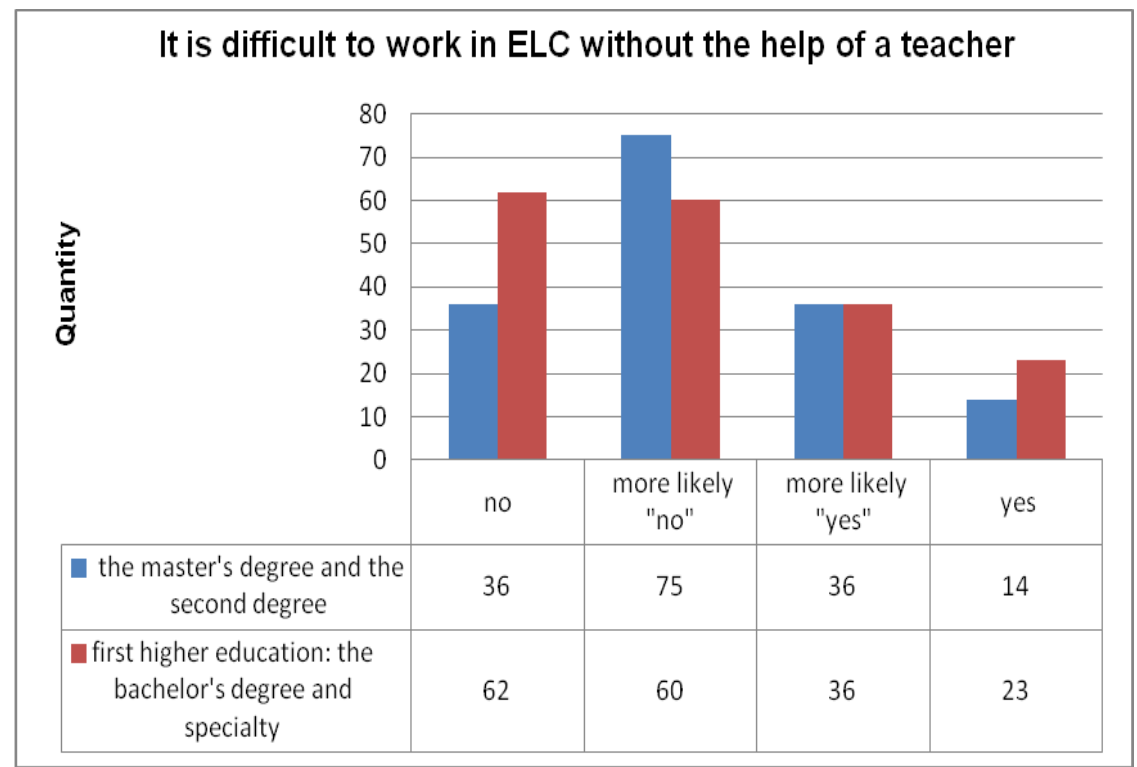

Fig. 1. Distribution of answers of students of two categories to the question about the difficulty of working in an electronic course without the help of a teacher.

There were no significant differences in responses to questions about student interactions with each other and with faculty members in the face-to-face program discovered. Students of both categories helped their classmates $65.8 \%$ and $67.0 \%$ at seminars respectively, $70.8 \%$ and $73.6 \%$ received help, and $56.5 \%$ and $53.5 \%$ often answered the teacher's questions. But, according to their reviews, $77 \%$ of undergraduates and $66.7 \%$ of students of the second higher education degree systematically studied ELC from the very beginning. At the same time, the statement that "I studied the ELC materials almost completely by myself and participated in no more than 2 face-to-face seminars or webinars" was supported by $51.4 \%$ of students, only $30.4 \%$ of undergraduates and students of the second higher education degree.

How justified is it to worry that students will lose the unique opportunity to communicate personally with their teachers when taking online courses? Is it true that a teacher is not needed? The assertion that "face-to-face meetings or webinars with teachers are simply not needed, video recording and contact through the forum are enough" was supported by $37.2 \%$ of graduate students and only $14.3 \%$ of students of first higher education degree.

At the same time, $39.9 \%$ of young people and only $17.4 \%$ of undergraduates and students of a second higher educational institution are ready to replace face-to-face courses with webinars. As a result, the former interacts more confidently with teachers only online, while the latter requires face-to-face studies and mixed learning.

The study has shown that senior students and more experienced students and young people appreciate the format of the ELC courses in applied mathematical statistics and more than two-thirds want to study other subjects in this format.

Interaction and mutual assistance at seminars are also typical for more than two thirds of both categories of students. More than two-thirds of students in both categories also confirmed their systematic work on the curriculum from the very beginning. At the same time, attendance at face-to-face seminars for graduate and second-degree students was better, with only a third claiming to have studied the course almost entirely on their own. 
The positive attitude of the majority of students to the idea of taking courses in other universities, including foreign ones, indicates the need to create MOOCs and a form of network interaction between universities. However, not everyone understands well that this is due to the need of interacting with the teacher only online, as well as to speak English while studying at a foreign university, which caused some contradictions in the views of the respondents. The problem of dishonest learning strategies worries many educators. Explaining the data of our survey, we can conclude that students of both categories tend to think that their fellow-students do not use this strategy, but it is impossible to prevent its use completely. When implementing the test, we pointed out that the implementation of the task under the camera or in the presence of a teacher, as well as external control, is not always feasible.

Perhaps training methods should be combined with external control to struggle against dishonest tactics. We believe that special attention should be paid to motivation of students to study electronic courses independently and systematically. The research hypothesis is only partially confirmed. Differences of opinion between graduate students, as well as students studying on the basis of higher education and students receiving their first higher education degree, as a rule, are not of a fundamental nature due to the different ways of answering the questions. For example, some respondents have the answer "quite yes". While others have the answer "yes". Secondly, undergraduates and university students spend a little more time each week on independent work at ELC. Tests are rated by them as more difficult, but at the same time they contribute to memorization of the material more often.

Based on the subjective assessment of students, the difficulty of reporting on the ecourse has a significant tendency to increase with age. However, the overwhelming majority of students in both groups have no apparent difficulties in learning online. Most students of both categories consider e-learning to be more interesting than traditional formats and do not associate learning in a digital environment with a decline in the quality of education, and also consider the introduction of e-learning courses to be relevant and timely. They evaluate Applied Mathematical Statistics in the format of ELC, in which most of them would like to study other subjects.

The seminar activities are characterized by most of the two categories of students as interactive and systematic work.

Students of the first higher education degree are more confident that only the online model can interact with faculty, while master's and second degree programs require faceto-face courses and mixed learning. Finally, as to the issue of unfair test-passing strategies, students believe that strict control will not solve the problem and cannot be completely eradicated.

\section{Conclusions}

Without comprehensive independent work it is impossible to use project making technologies and ICT for teaching students of universities for the Humanities, as well as the successful formation of information and communication skills. Students should be able to choose that form of mastering the materials, access to which is most interesting for them, thereby increasing their internal motivation and allowing them to form information and communication skills most effectively [7].

The introduction of project making technology and its integration with technology in the field of education makes it possible to bring training as close as possible to future professional activities. At the same time, students enrolled in the course "Information and communication technologies in education" at all stages, in the course of reflective polls conducted by the students themselves, note an increase in the level of their own information 
culture and hope to optimize their activities with the help of ICT. The control tests conducted by teachers also confirm the successful development of students' ability to master ICT effectively.

\section{References}

1. O.N. Oleinikova, A.A. Muravyova, Quality of Vocational Education, 111 (2017)

2. N.A. Dmitrievskaya, G.I. Goremykina, Modeling a Management System Based on the Results of Functioning of a Smart University in the Context of Digitalization of the Economy and Society, E-Learning Stakeholders and Researchers Summit, 39-46 (2018)

3. M.V. Klimenskikh, A.V. Maltsev, A.V. Khalfin, Motivational and Cognitive Features of Online Students, E-Learning Stakeholders and Researchers Summit, 146-154 (2018)

4. A.V. Bogdanova, Informatization of the Educational Space, 4(15), 57-60 (2018)

5. V.A. Bolotov, Pedagogical Education in Russia in the Context of Social Change: Principles, Technologies, Management, 290 (2017)

6. A.A. Verbitsky, Education in the Modern Educational Paradigm, Pedagogy, 3, 3-16 (2016)

7. V.V. Davydov, Theory of Developmental Learning, 544 (2016)

8. N.V. Dvoryanchikov, T.V. Kalashnikova, L.S. Pechnikova, N.V. Frolova, The Use of E-learning in the Educational Process: Problems and Prospects, Psychological Science and Education, 21(2), 76-83 (2016)

9. M.A. Safronova, N.V. Bysik, Description of the Project of Modernizing Teachers' Training Education, Psychological Science and Education, 3, 78-86 (2018)

10. J. Seely Brown, Growing Up Digital: How the Web Changes Work, Education, and the Ways People Learn, Change Magazine, 32, 11 (2016)

11. D. Tapscott, Growing Up Digital: The Rise of the Net Generation, 15 (2018) 